\title{
IDENTIFICAÇÃO E ANÁLISE DAS MANIFESTAÇÕES PATOLÓGICAS EM EDIFICAÇÕES HISTÓRICAS LOCALIZADAS NO MUNICÍPIO DE ARACATI - CE
}

\author{
FREITAS, INGRID \\ Engenheira Civil \\ UFERSA \\ Ceará; Brasil \\ ilourranybf@gmail.com \\ MAIA, GABRIELA \\ Engenheira Civil \\ PITÁGORAS \\ Ceará; Brasil \\ gabsronc@gmail.com
}

\author{
JÁCOME, CAMILA \\ Engenheira Civil \\ UFERSA \\ Ceará; Brasil \\ camilajacome89@gmail.com
}

\section{RESUMO}

O conjunto arquitetônico e paisagístico do município de Aracati, localizado na região do litoral Leste-Jaguaribe do estado do Ceará, foi tombado como patrimônio histórico nacional pelo Instituto do Patrimônio Histórico e Artístico Nacional (IPHAN) em 2001, sendo constituído por igrejas, sobrados e edificações variadas que juntas totalizam mais de 2500 edificações. Dessa forma, é de extrema importância que essas edificações sejam preservadas, pois guardam consigo parte da história do nosso país. Entretanto, verificou-se que muitas apresentam alguns danos, externos e internos, devido tanto à fatores ambientais quanto à falta de manutenção. Diante disto, o objetivo do presente trabalho é identificar e analisar as manifestações patológicas presentes em algumas das edificações do centro histórico aracatiense, o que poderá auxiliar no processo decisório de futuras manutenções.

Palavras-chave: manifestações patológicas, levantamento, construção histórica.

\begin{abstract}
The architectonic and paisagistic complex of the city of Aracati, located in the region of the East Coast of Jaguaribe of the state of Ceará, was considered as national historical patrimony by the Instituto do Patrimônio Histórico e Artístico Nacional (IPHAN) in 2001, being constituted by churches and varied buildings that together total more than 2500 buildings. Thus, it is extremely important that these buildings are preserved, because they keep part of the history of our country. However, it was found that many of them present some damage, external and internal, due to both environmental factors and lack of maintenance. Given this, the objective of this work is to identify and analyze the pathological manifestations present in some of the buildings in the historic center of Aracati, which may help in the decision-making process of future maintenance.
\end{abstract}

Keywords: pathological manifestation, survey, heritage construction.

\section{INTRODUÇÃO}

A Constituição Federal de 1988, em seu artigo 216, afirma que patrimônio histórico e cultural é todo bem material e imaterial, que se traz consigo, de alguma forma, a identidade, ação e memória de um povo. Para Figueiredo (2014), o patrimônio cultural é formado por todos os monumentos, conjuntos e sítios integrados que identificam-se com seu entorno, seja ele natural ou artificial. Desta forma, preservar essas edificações é uma forma de respeito e manutenção da cultura e história de uma determinada população.

Entre os estados do Brasil, o Ceará é um dos que apresenta diversas cidades com edificações deste tipo. Dentre esses municípios está Aracati, localizado no litoral do estado, cuja maior parte das edificações datam do período colonial e ainda retratam a identidade da época em que a economia baseava-se na pecuária e produção de algodão, fatores estes que contribuíram para o seu tombamento, por parte do Instituto do Patrimônio Histórico e Artístico Nacional (IPHAN), em 2001. 
Apesar do tombamento e reconhecimento da importância dessas edificações para a cidade, sabe-se que assim como qualquer outra edificação, com o decorrer do tempo surgem manifestações patológicas, sejam devido à ação de intempéries, a problemas na etapa de execução da construção ou à falta de manutenção. Diante disto, este trabalho tem como objetivo realizar a identificação e análise das manifestações patológicas presentes em algumas das edificações pertecentes ao centro histórico do referido município.

\section{ESTUDO DE CASO}

Aracati é um município localizado na região litorânea do Estado do Ceará, distante $150 \mathrm{~km}$ da capital cearense, Fortaleza. O município, que foi fundado no ano de 1747, teve parte de seu núcleo urbano tombado pelo Instituto do Patrimônio Histórico e Artístico Nacional (IPHAN) como patrimônio nacional no ano de 2001. Considerada como uma das mais belas cidades do Nordeste, Aracati é a terra onde nasceu o pianista clássico Jacques Klein, o romancista Adolfo Caminha, o abolicionista Dragão do Mar, o Revolucionário Eduardo Angelim, o jurista e escritor Beni Carvalho e tantos outros. Macedo (2010) afirma que Aracati possui um dos mais arrojados patrimônios, não somente histórico, mas também cultural e arquitetônico: o recorte centenário de suas Igrejas e de seus Casarões, os beirais e cornijas de suas fachadas, os lambris e os jacarés de suas austeras residências revelam riqueza arquitetônica e cultural.

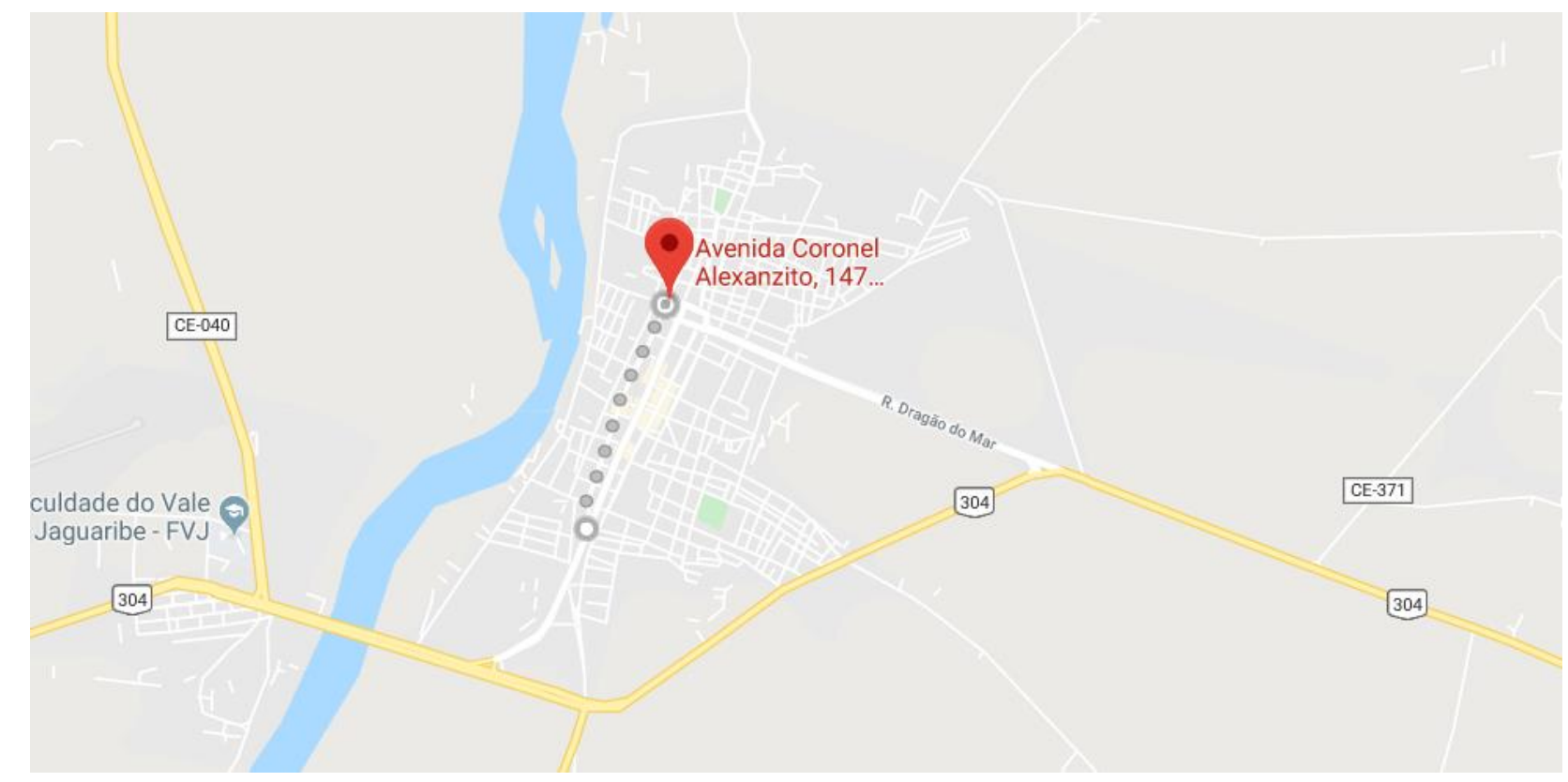

Figura 1: Localização do Centro Histórico de Aracati.

De acordo com o IPHAN, Aracati detém grande patrimônio histórico-cultural. O conjunto histórico da cidade é constituído por igrejas, sobrados e edificações variadas que juntas totalizam mais de 2.500 edificações construídas e decoradas com azulejos portugueses de alto valor. Os bens tombados estão localizados, em sua grande maioria, no centro histórico de Aracati, rua extensa que atravessa parte da cidade. A Figura 1 apresenta o mapa da cidade onde é representada a extensão da área onde se encontram grande parte das construções históricas.

Com base no exposto, o presente estudo visa caracterizar os danos atuantes na deterioração de fachadas de três edificações históricas na cidade de Aracati. Entre elas destaca-se o casarão onde nasceu o escritor Adolfo Caminha (Figura 2), edificação detentora de grande riqueza histórica e cultural da cidade. O casarão está situado no centro histórico de Aracati, na Avenida Coronel Alexanzito, popularmente conhecida como Rua Grande. 


\section{СВРАT 2020 \\ CONGRESSO BRASILEIRO DE PATOLOGIA DAS CONSTRUÇÕES \\ DE 15 A 17 DE ABRIL | FORTALEZA - CE}

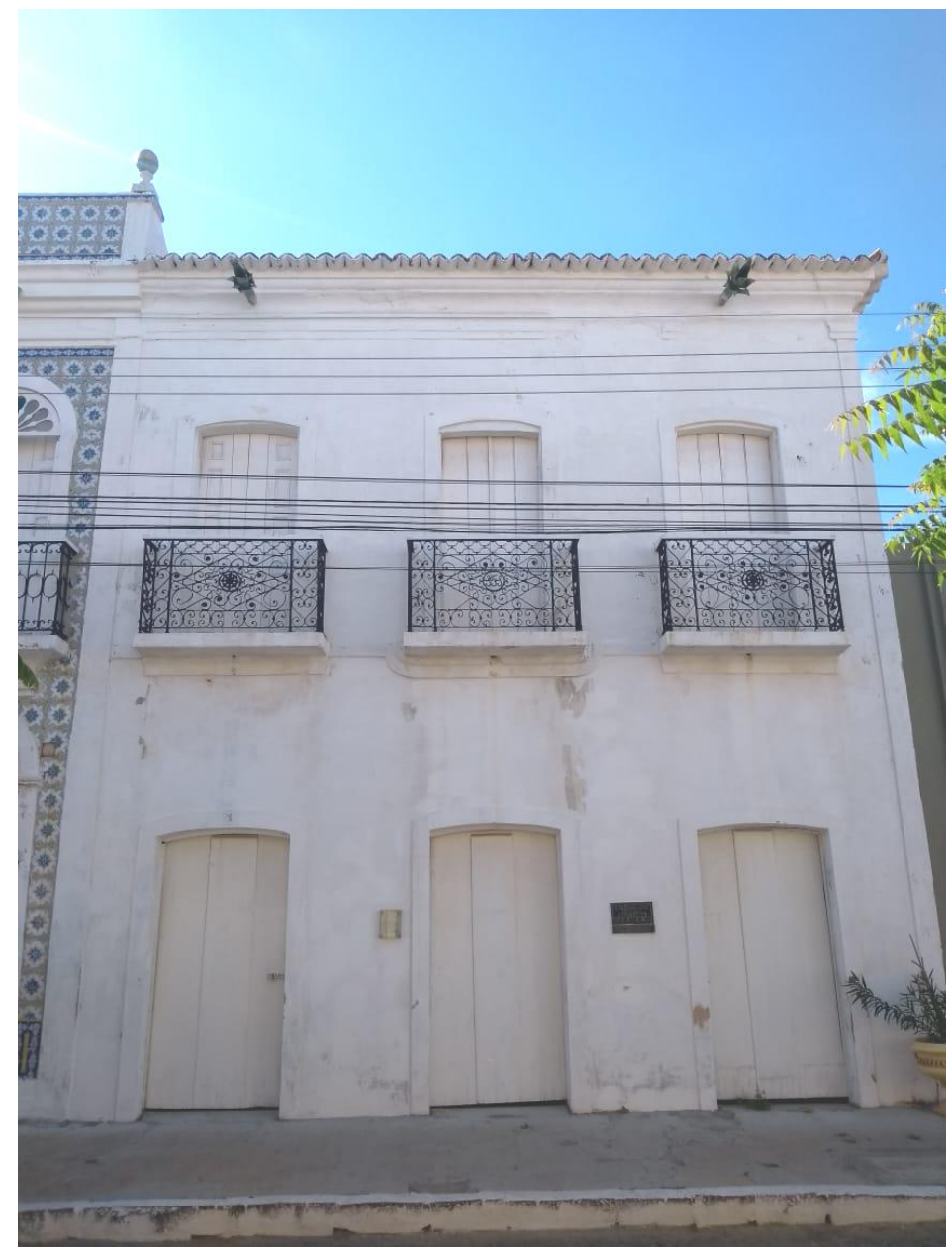

Figura 2: Vista frontal da casa de Adolfo Caminha.

A edificação em estudo é constituída de um sobrado feito de alvenaria de tijolo cerâmico maciço e com antigas madeiras no assoalho e no teto. É importante ressaltar que a edificação em estudo já passou por algumas reformas. Na Figura 2 é possível observar também os detalhes da fachada, que apresenta pintura em tinta branca como revestimento, três entradas principais com portas de madeira, três varandas contendo portas de madeira e grades com acabamento colonial e dois jacarés para escoamento de água.

Para o levantamento e a análise das danos existentes nas fachadas, utilizou-se como metodologia inspeção preliminar, vistorias técnicas datadas em dezembro de 2019 e análise das condições de manutenção das fachadas (levantamento fotográfico dos danos encontrados, levantamento dos danos e diagnóstico), a fim de registrar as principais informações. As análises foram feitas apenas nos ambientes externos das edificações, tendo em vista a importância dessas edificações para o patrimônio histórico de Aracati e também levando em consideração a facilidade de acesso na realização dos levantamentos.

As manifestações patológicas encontradas se agrupam em quatro tipos, sendo eles: descolamento de revestimento, umidade, fissuras/trincas e irregularidade do acabamento (VIANA, 2016). No presente trabalho serão analisadas estas manifestações, considerando que para a irregularidade do acabamento será analisada a sujidade nas fachadas.

As fachadas das edificações foram cautelosamente analisadas, sendo feitos registros de todas as manifestações patológicas identificadas. Posteriormente tais manifestações foram descritas a fim de se detectar os danos mais frequentes e suas possíveis causas foram discutidas.

\section{RESULTADOS E DISCUSSÃO}


As edificações apresentaram danos, tais como diversas fissuras, umidade, desplacamento de pintura e de revestimento cerâmico das fachadas, desplacamento da pintura das portas, além de sujidade nas fachadas. Em alguns pontos foram observadas eflorescências e oxidação. Para uma melhor compreensão do texto, os resultados foram divididos em três seções, sendo cada uma delas responsável por apresentar os danos externos nas fachadas de três diferentes edificações históricas do município de Aracati.

\subsection{Casarão da Família Sales}

O casarão pertence a uma tradicional família de Aracati, os Sales. Trata-se de uma edificação subdivida em térreo e $1^{\circ}$ andar, que apresenta uma quantidade significativa de manifestações patológicas e encontra-se em um estado de conservação alarmante, como pode-se observar na Figura 3, através da fachada principal do imóvel.

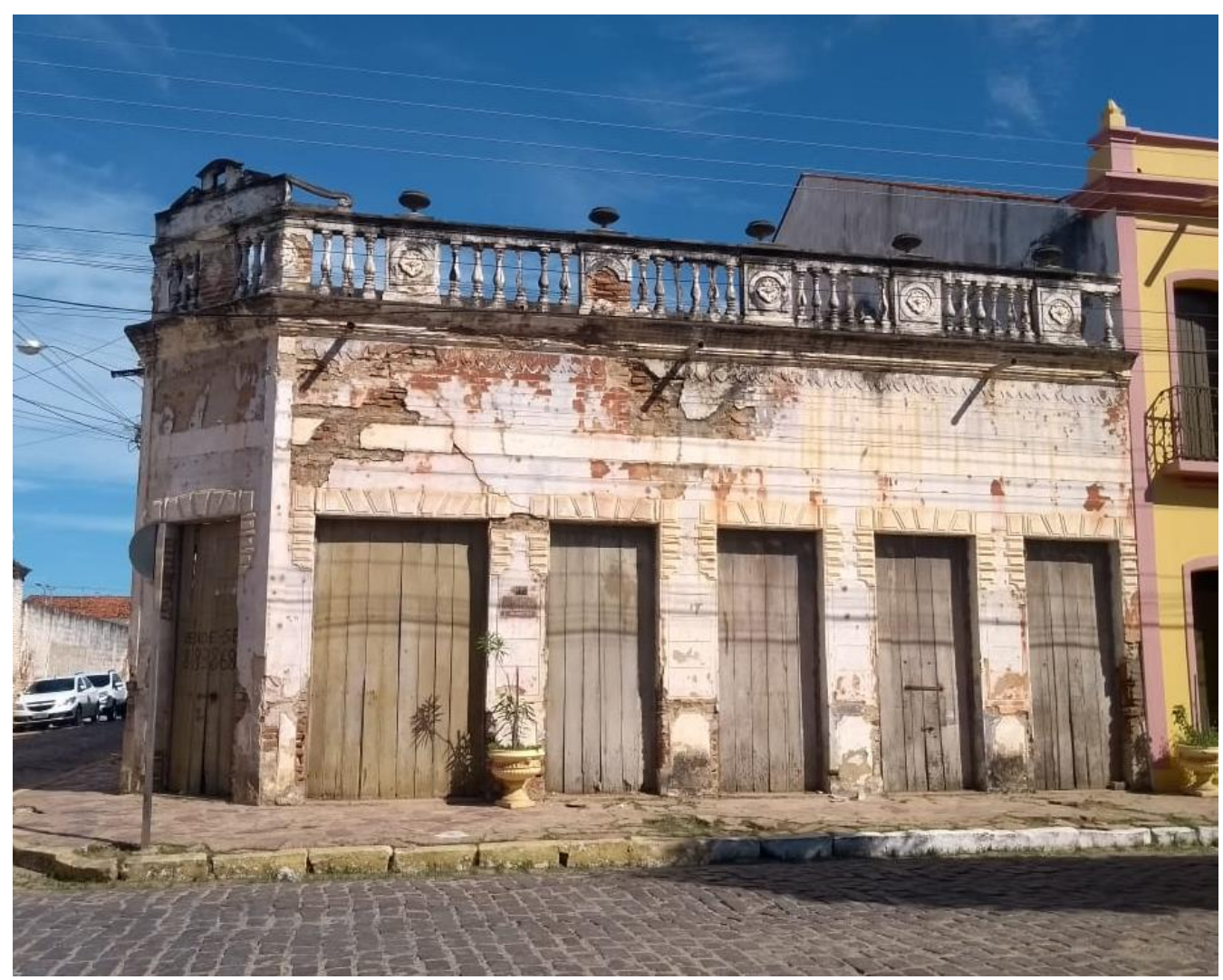

Figura 3: Fachada principal Casarão da família Sales.

O sobrado não passa por reformas há um tempo considerável. Na Figura 4 observa-se que em grande parte da fachada há o descolamento da argamassa de revestimento e o descascamento da pintura. Tais manifestações patológicas surgem em decorrência da perda de aderência entre o revestimento e a superfície. Dentre as prováveis causas para o seu aparecimento pode-se apontar a ausência de manutenção, que acarretou no término de sua vida útil, umidade e uso de materiais inadequados durante a construção. Observa-se também na fachada a presença de fissuras, cuja causa pode ser explicada pelo fenômeno da retração. Trata-se de uma região com exposição direta ao sol, o que pode ter levado à retração do revestimento devido à evaporação excessiva da água da argamassa. Além disso, observou-se a presença de manchas e mofo na fachada, manifestações provenientes de umidade. Elas ocorrem devido à infiltração de água que fica aderida ocasionando manchas e mofo. 

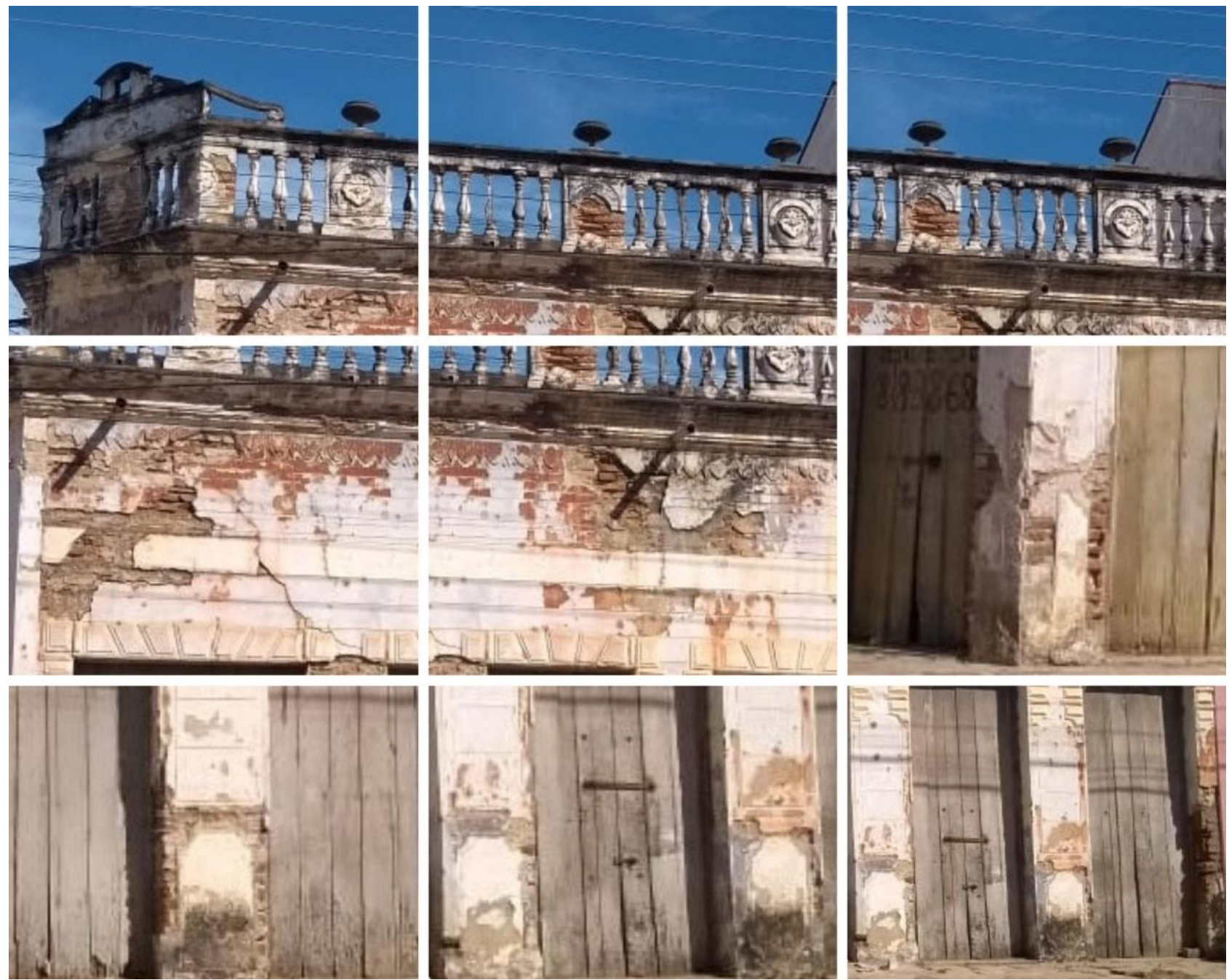

Figura 4: Manifestações patológicas na fachada do casarão.

\subsection{Casarão do escritor Adolfo Caminha}

O casarão do escritor Adolfo Caminha - mostrado na Figura 2 -, um patrimônio histório e cultural que foi uma homenagem do Instituto Museu Jagaribano, já passou por uma reforma e agora apresenta algumas manifestações patológicas no exterior da edificação como: fissuras, manchas de infiltrações, descolamentos de componentes da fachada e descascamento da pintura. 

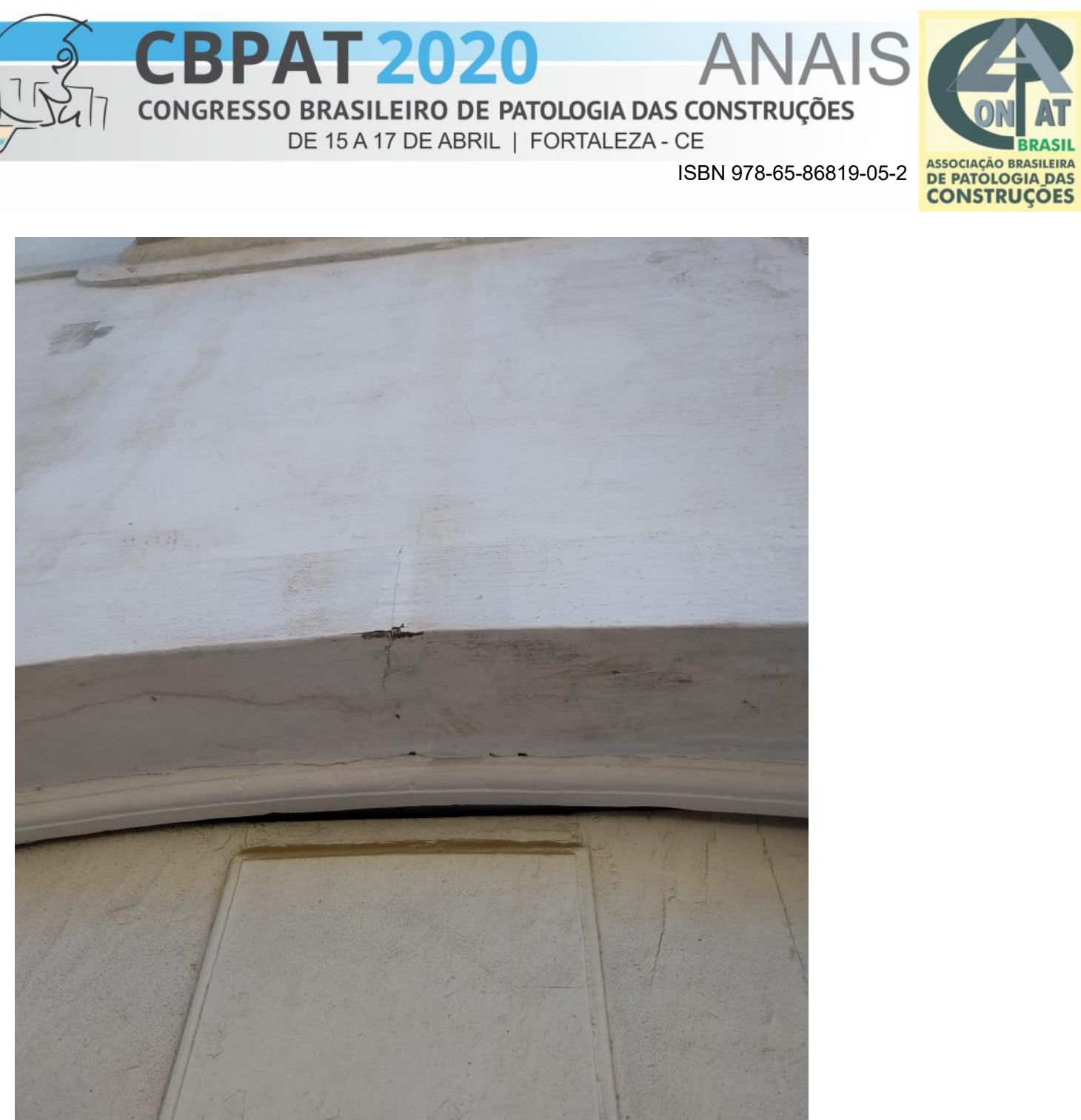

Figura 5: Fissura localizada na parte superio da parede da fachada.

A fissura visível na Figura 5 tem como provável causa a retração ou expansão dos materiais constituintes da fachada principalmente no que diz respeito à pintura e à argamassa do revestimento -, decorrentes da grande variação de temperatura entre as estações.

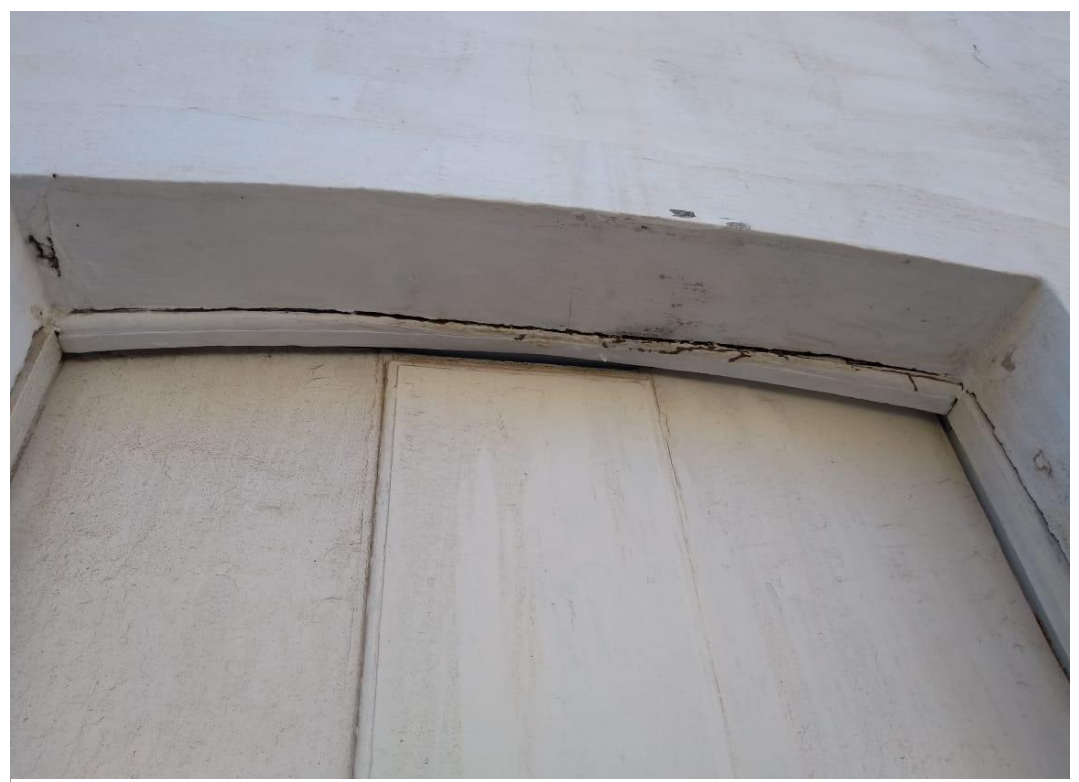

Figura 6: Descolamento entre a porta e parte superior da parede. 


\section{CBPAT 2020 \\ CONGRESSO BRASILEIRO DE PATOLOGIA DAS CONSTRUÇÕES \\ DE 15 A 17 DE ABRIL | FORTALEZA - CE}

O descolamento entre a parte superior da porta e a superfícia acima - como pode ser visto na Figura 6 - ocorre devido à retração da argamassa, exposta ao sol durante grande parte do dia. A falta de manutenção em conjunto com a exposição às intempéries levou ao descascamento da pintura da fachada e ao surgimento das manchas observadas, como observase na Figura 7.

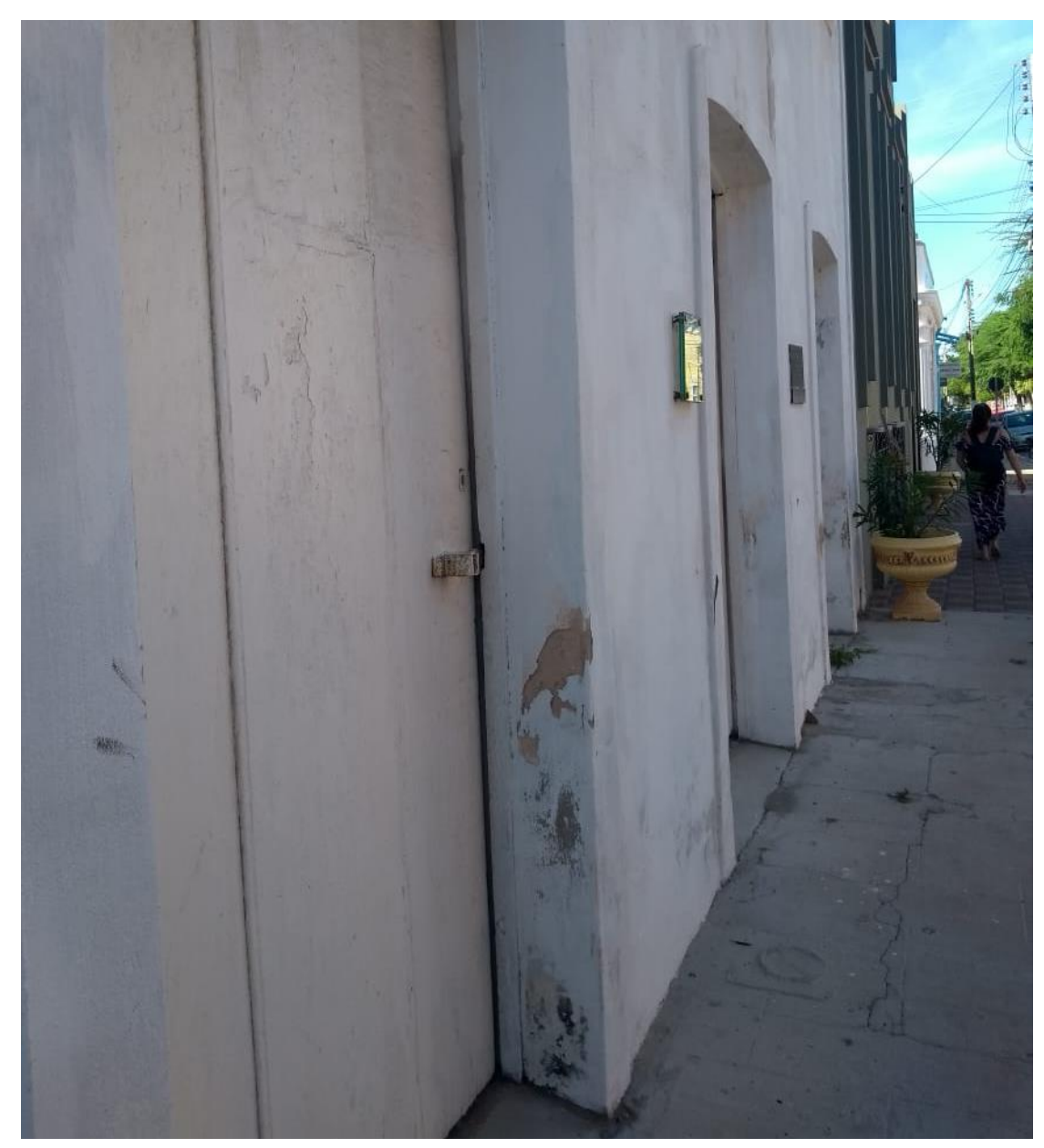

Figura 7: Descascamento da pintura e manchas na fachada.

\subsection{Casarão Azul da Rua Grande}

O casarão azul da Rua Grande, como é conhecida a principal rua do centro histórico aracatiense, trata-se de uma edificação de apenas um pavimento, cuja fachada é revestida com azulejos azuis de origem portuguesa, com duas portas e uma janela que possuem vitrais em sua parte superior, como vê-se na Figura 8.

As manifestações patológicas visíveis na fachada principal são: descascamento da pintura, desplacamento, manchas de infiltração e mofo, fissuras e descolamentos de componentes da fachada, sendo que o fator determinante de todos esses problemas é a ausência de manutenções preventivas durante a vida útil da edificação, o que poderia prolongá-la. Mas, além disso, outros fatores podem ocasionar esses problemas, podendo-se mencionar, neste caso, a retração e expansão dos componentes devido à ação de fatores ambientais - alteração da temperatura, ação da chuva e exposição prolongada ao sol. 


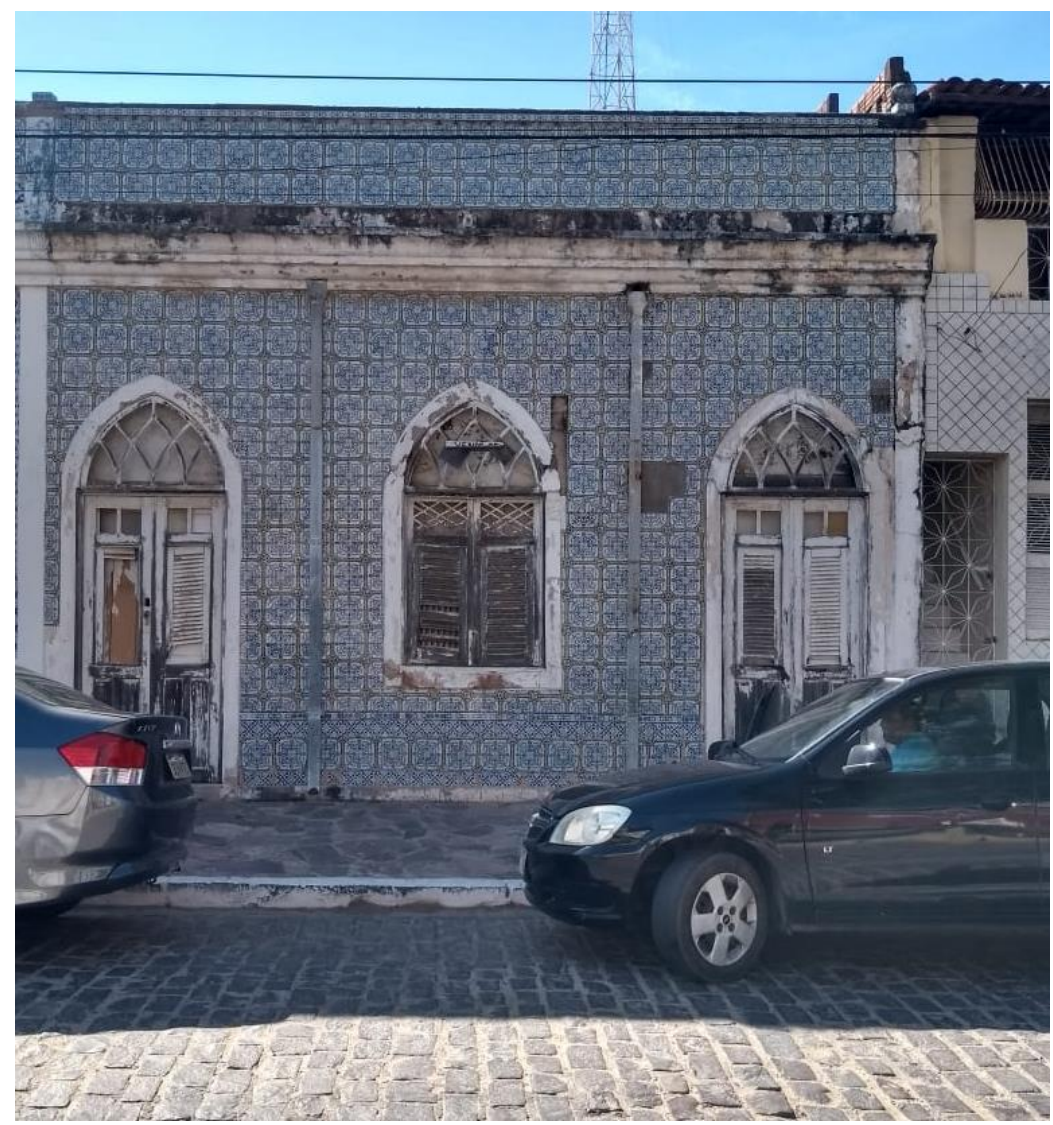

Figura 8: Colocar legenda

\section{CONCLUSÃO}

Neste artigo foram apresentadas edificações da cidade de Aracati-CE tombadas como patrimônio histórico e cultural do Brasil: o casarão onde nasceu escritor Adolfo Caminha e outros dois casarões existentes no município. Analisou-se as manifestações patológicas das fachadas das edificações, buscando identificar seus tipos e possíveis origens. Por metodologia de inspeção preliminar e vistorias técnicas das fachadas dos edifícios, percebeu-se que em todas os casarões observados há manifestações patológicas em comum, como fissuras, manchas de infiltração, descolamento da argamassa e descascamento da pintura da fachada, mofo, às quais frequentemente aparecem em edificações em que não há manutenção ao longo de sua vida útil.

Diante disso, percebe-se a importância da conservação e manutenção de edificações desse tipo, pois carregam consigo a memória da história e cultura de um povo, contribuindo para que estas sejam perpetuadas ao longo das gerações.

\section{REFERÊNCIAS}

ASSOCIAÇÃO BRASILEIRA DE NORMAS TÉCNICAS. NBR 10520: Informação e documentação - Citações em documentos - Apresentação. Rio de Janeiro, 2002.

ASSOCIAÇÃO BRASILEIRA DE NORMAS TÉCNICAS. NBR 6023: Informação e documentação - Referências Elaboração. Rio de Janeiro, 2018.

BARBOSA, Maria Edivani Silva. Aracati (ce) no período colonial: espaço e memória. 2004. 205 f. Dissertação (Mestrado) - Curso de Mestrado Acadêmico de Geografia, Universidade Estadual do Ceará, Fortaleza, 2004.

FIGUEIREDO, Margareth Gomes de. Valorização do sistema construtivo do património edificado. 2014. 203 f. Tese (Doutorado) - Curso de Engenharia Civil, Universidade de Aveiro, Aveiro, 2014. 
HERNÁSNDEZ-OLIVARES, F.; BARLUENGA, G. Fire performance of recycled rubber-filled high-strength concrete. Cement and Concrete Composites, v. 34, p. 109-117, 2004.

IPHAN - Instituto do Patrimônio Histórico e Artístico Nacional. $4^{\mathrm{a}}$ Superintendência Regional (CE/RN). Aracati-CE - Estudo para Tombamento Federal. V.1 e 2, 1998.

MACEDO, D. A casa de Adolfo Caminha. Associação Artístico Cultural Lua Cheia. Disponível em: <http://luacheia.art.br/aracati/memoria/180-a-casa-de-adolfo-caminha.html . Acesso em: 10 de dezembro de 2019.

VIANA, M. F. Conjunto histórico e arquitetônico da cidade de Viçosa do Ceará: dos percursos da patrimonialização (1997-2006). Programa de Mestrado Acadêmico em História / Dissertação (Mestrado) Universidade Estadual do Ceará. Fortaleza, 2016. 